\title{
Physical Research of Carbon Nanomaterials in the Microwave Range
} Publisher: IEEE

\section{Olga Tanana; Yury Golubev}

\begin{abstract}
: devices processing and transmitting microwave signals and other applications.

Published in: 2020 IEEE Ukrainian Microwave Week (UkrMW)

Date of Conference: 21-25 Sept. 2020

Date Added to IEEE Xplore: 11 November 2020

ISBN Information:

INSPEC Accession Number: 20154269

DOI: $10.1109 /$ UkrMW49653.2020.9252746

Publisher: IEEE

Conference Location: Kharkiv, Ukraine
\end{abstract}

Techniques have been developed for measuring the electrophysical characteristics of carbon nanomaterials in the microwave range. The materials studied surpass all existing and used at present radio-absorbing materials in radio engineering in all electrophysical characteristics by several times. The results of an experimental study of the electrophysical characteristics of carbon nanomaterial samples make it possible to recommend them for practical use in the microwave range of wavelengths as lightweight composite materials for highly efficient electromagnetic shields, conducting and reflecting electromagnetic radiation structures in

References

1.P.J.F. Harris, Carbon Nanotubes and Related Structures: New Materials for the TwentyFirst Century, Cambridge, UK:Cambridge University Press, pp. 277, 1999.

Show in Context CrossRef Google Scholar

2.V.N. Popov and P. Lambin, "Vibrational and related properties of carbon nanotubes" in Carbon Nanotubes: From Basic Research to Nanotechnology, Netherlands:Springer, pp. 69-88, 2006.

Show in Context CrossRef Google Scholar

3.A.V. Yeletsky, "Carbon nanotubes", UFN, vol. 167, no. 9, pp. 945-972, 1997.

Show in Context CrossRef Google Scholar

4.E.G. Rakov, "Production of carbon nanotubes", Advances in chemistry, vol. 69, no. 1, pp. 41-59, 2000.

Show in Context Google Scholar

5.I.I. Bobrinetsky, K.V. Gorshkov, V.V. Losev and A.A. Stroganov, "The use of carbon nanotubes in test structures for calibrating probes of atomic force microscopes", $V$ 
international conference Carbon: fundamental problems of science materials science technology, pp. 75, 2006.

Show in Context Google Scholar

6.I.I. Bobrinetskii, V.K. Nevolin, M.M. Simunin and S.V. Khartov, "Carbon nanotube chemical ethanol vapour growth methods for application in electronics and nanomechanics", Book of Abstracts 8th Biennial International Workshop Fullerenes and Atomic Clusters, pp. 202, 2007.

Show in Context Google Scholar

7.I.I. Bobrinetsky, A.N. Bulatov and V.K. Nevolin, "The first mock-ups of functional elements of carbon nanoelectronics", Nanotechnology, vol. 2, no. 6, pp. 9-13, 2006.

Show in Context Google Scholar

8.D. Altman, Devices over high frequencies, pp. 488, 1968.

Show in Context Google Scholar

9.V. Karpovich, V. Rodionova, A. Rakov, I. Anoshkin and O. Philipenok, "Electromagnetic wave absorption and reflection by carbon nanotube composites", The sixth international Kharkov symposium on physics and engineering of microwaves millimeter and submillimeter waves and workshop on terahertz technologies Symposium Proceedings vol.2 Kharkov Ukraine June 25-30. Edited by A.Kostenko. A. Usikov Institute of RadioPhysics and Electronics of NAS of Ukraine, pp. 825-827, 2007.

Show in Context Google Scholar

10.G.Ya. Slepyan, V.N. Skresanov, V.N. Rodionova, V.A. Karpovich, M.P. Natarov and O.V. Filipenok, "Irregular-Waveguide elements coupling high-Q resonators with single-mode waveguides", Journal of Communications Technology and Electronics, vol. 53, no. 2, pp. 184-189, 2008.

Show in Context CrossRef Google Scholar

11.Technical specifications.

Show in Context Google Scholar

12.S.A. Zhdanok, A.V. Krauklis, I.F. Buyakov, V.A. Karpovich, V.N. Rodionova and O.V. Tanana, "Radio absorbing properties of carbon nanomaterials", Nanotechnology, no. 2, pp. 72-75, 2011.

Show in Context Google Scholar

13.V.A. Labunov, F.F. Komarov, V.A. Karpovich, V.N. Rodionova, I.V. Komissarov, V.B. Karpovich, et al., "Electromagnetic characteristics of nanocarbon composite materials in the microwave range" in Fullerenes and nanostructures in condensed matter: coll. scientific senior / NAS of Belarus Institute of heat and mass transfer named after A.V. Lykov, Minsk:BSU Publishing Center, pp. 14-22, 2011. 